\title{
Optimization of Composite Layering Effect Based on Measured Formation Fracture Height to Length Ratios
}

Abdunaser O. Susi ${ }^{\star *}$, Mahmoud A. Mahrous ${ }^{2}$, Khalid A. Elwegaa ${ }^{3}$, Paul L Sims ${ }^{4}$, Iloyd R. Heinz ${ }^{5}$, Mohamed. Y. Soliman ${ }^{6}$ George B. Asquith Mahmoud Elsharafi ${ }^{8}$,

1,3,4,5 Department of Petroleum Engineering, Texas Tech University, USA

${ }^{2,7}$ Department of Geosciences, Texas Tech University, USA

${ }^{6}$ Department Chair, Petroleum Engineering, University of Houston, USA

${ }^{8} \mathrm{McC}$ coy School of Engineering, Midwestern state University, Wichita Falls, TX USA

\begin{abstract}
This study achieves two main goals. First, it develops a method that uses the Composite Layering Effect (CLE) Equation to predict the behavior of potential fractures in conventional and unconventional reservoirs from core samples. The second goal of this study is to determine how different mineralogical and elemental components affect the behavior of fractures predicted using the CLE equation. After the samples are fractured, X-ray Powder Diffraction $(\mathrm{XRD})$ and $\mathrm{X}$-ray Fluorescence (XRF) techniques are executed to measure the mineralogical and elemental compositions of the core samples respectively. In this method, core samples are first obtained from the formation. Next, X-Ray Computed Tomography (CT) is used to determine if core samples have preexisting fractures. The samples are then fractured slightly using Uniaxial Compressive Strength (UCS), in which a compressive-strength machine initiates fractures by applying uniaxial load and stopping automatically upon reaching a predetermined load. CT then confirms the existence of the new fractures, and Image $J$ interprets the height-length ratio of each fracture. These results are used in calculating the CLE. The results of these experiments revealed the relationship between the mineral and elemental compositions of the rocks and the crack dimensions. It was seen that the presence of quartz and clay minerals had the strongest influence on the CLE value due to the brittle behavior of the quartz and ductile behavior of the clay minerals (nacrite). The highest CLE value was recorded for the shale sample that had a preexisting fracture. The fracture patterns developed in the shale samples were mainly parallel to one another. In contrast, the fracture patterns developed in sandstones started out parallel and later merged together to form a connected fracture network.
\end{abstract}

Keywords: Height-length ratio; Composite layering effect; X-Ray Computer Tomography (CT); X-ray Powder Diffraction (XRD); X-ray Fluorescence (XRF)

\section{Introduction}

Hydraulic fracturing technologies were used to improve the production of tight reservoirs, such as shale formations, by creating a flow path in areas of low permeability [1]. This technology has been in practice since the late 1940s, and since then, it has undergone many changes to improve affectivity, such as fracture design and the use of advanced fracking fluids. It is well known that there are multiple mechanisms controlling fracture propagation through the formation (fracture containment). These include complex geologic layering, heterogeneity in formation rock properties, high fluid leak off, the presence of natural fractures, and the presence of layers of high permeability [1]. Teufel and Clark [2] conducted laboratory hydraulic fracture experiments coupled with elastic finite element studies to investigate the factors that control fracture growth through the layer interface. They concluded that two distinct geological conditions may prevent the vertical growth of hydraulic fractures. The first such condition is weak interfacial shear strength of the fractured layer, and the second is a compressional increase in the minimum horizontal stress in the bounding layer [2]. Furthermore, Soliman et al. [3] successfully developed a new methodology to obtain the optimum fracture treatment design which could be applied to a wide range of reservoir conditions. The newly developed technique has the capability to determine appropriate fracture conductivity, as well as the optimum fracture length. It also reconciles it with reservoir fracture growth behavior [3]. It is well documented that the fracture geometry and orientation are major factors in designing hydraulic fracture treatments aimed at improving natural gas recovery from tight gas sand reservoirs
[2]. Fractures are effective at improving hydrocarbon production due to the increase in reservoir permeability associated with the formation of new permanent paths. It is crucial to investigate the distribution and geometry of fractures in the rock matrix and to identify the factors that trigger their development. There are several ways to investigate fracture geometry and networks such as thin section analysis using regular microscopes, regular porosity and permeability laboratory measurements, scanning electron microscopy (SEM), and hand specimen analysis. These techniques provide an excellent evaluation for fracture networks, but they are low resolution 2D images and take substantial amounts of time to complete. Furthermore, preparing the samples for these evaluations requires sophisticated techniques. Preparation of the sample for analysis can induce fractures, introducing error into the sample evaluation. To combat these problems, CT can be used to investigate the internal structure of the rock and provide $3 \mathrm{D}$ visualization of the fracture networks in a non-destructive way. There are several factors that influence the distribution and development of fracture networks in shale reservoirs, including tectonic and nontectonic factors [4]. Common nontectonic factors considered are

Corresponding author: Abdunaser O. Susi, Department of Petroleum Engineering, Texas Tech University, USA, Tel: +1 806-742-3573; E-mail: Abdunaser.o.susi@ttu.edu

Received July 02, 2018; Accepted July 25, 2018; Published July 29, 2018

Citation: Susi AO, Mahrous MA, Elwegaa KA, Sims PL, Heinz IR, et al. (2018) Optimization of Composite Layering Effect Based on Measured Formation Fracture Height to Length Ratios. J Pet Environ Biotechnol 9: 376. doi: 10.4172/21577463.1000376

Copyright: ( 2018 Susi AO, et al. This is an open-access article distributed under the terms of the Creative Commons Attribution License, which permits unrestricted use, distribution, and reproduction in any medium, provided the original author and source are credited. 
lithology, mineralogical composition of the rock, shale thickness layer, TOC, rock mechanics, and clay minerals [5]. The most common methods used in mineralogical composition identification are XRD and scanning electron microscopy (SEM) combined with energy dispersive spectroscopy (EDS). CT was used intensively in rock fracture characterization [6-10].

Unfortunately, there has not been much work done relating the fracture density, height, and depth to the mineralogical composition of the host rock using X-ray computed tomography in conjunction with $\mathrm{XRD}$. Therefore, the objective of this research is to investigate the effect of the mineralogical and chemical composition of the host rock on the fracture geometry and the fracture height. The method used herein is a combination between CT and XRD analysis. A total of three shale samples and three sandstone samples were used to compare between two different types of lithologies (Shale and sandstone). This study provides an experimental explanation to the generated equation used for calculating the composite layering effect (CLE) and its relationship to the fracture height provided by Susi et al. [11].

\section{$\mathrm{X}$-ray computed tomography principles (CT)}

Understanding the physics behind CT scanning is important in effectively interpreting the data. The CT scanning procedure starts by mounting the sample on a sample holder inside the CT scanning instrument and showering it with an X-ray beam produced from an $\mathrm{X}$-ray source (X-ray tube). Upon interaction between the sample and the X-ray beam, the beam gets partially attenuated by the sample matrix as it passes through it. Beam attenuation is controlled by the density and the atomic number of the scanned sample as well as the beam energy used in the scan. The relationship between the intensity of the incident beam and the final beam (transmitted intensity) resulting from a monochromatic beam passing through an object is governed by Lambert Beer's law:

$$
\mathrm{I}=\mathrm{I}_{0} e^{(-\mu \mathrm{X})}
$$

Where $I$ is the final transmitted beam intensity, $I_{0}$ is the initial photon intensity $(\mu)$ is the linear attenuation coefficient of the sample $\left[\mathrm{L}^{-1}\right]$, and $\mathrm{X}$ is the sample thickness. The linear attenuation coefficient of the sample $(\mu)$ depends on the electron density of the sample, bulk density of the sample, and the photon energy used in the scan. As the density of the sample being scanned increases, the image will appear brighter due to the higher attenuation of the beam as it passes through the sample, whereas points with lower density will appear darker due to less beam attenuation. For example, quartz particles will appear brighter than plagioclase because quartz has higher density than plagioclase. This higher density absorbs more photons and increases the linear attenuation coefficients $(\mu)$ of the beam. Since most of the samples are not homogenous, which results in different levels of beam attenuation throughout each sample, a new equation was developed for inhomogeneous samples [12]. The equation as follow:

$$
\mathrm{I}=\mathrm{I}_{0} e^{-\int_{A}^{B} \mu(x, y) d l}
$$

Where $\mathrm{A}$ is the entrance point of the beam and $\mathrm{B}$ is the exit point of the beam. The integration over the area between the two points will provide a more accurate linear attenuation value $(\mu)$ for inhomogeneous materials. The CT number represents the average attenuation coefficient for each voxel. This is then stored in the reconstructed 2D images. The unit for measuring the CT number is the Hounsfield unit (HU), and it is expressed as follow:

$$
C T=1000 \frac{\mu-\mu_{w}}{\mu_{w}}
$$

Where $\mu_{w}$ the linear attenuation coefficient of is pure water and is defined as $0 \mathrm{HU}$. In contrast, air is represented by $-1000 \mathrm{HU}$. The principle behind CT scanning is extensively explained by Ketcham et al., Baker et al., and Van Geet et al. [13-15].

\section{Materials and Methods}

\section{X-ray computed tomography $(\mathrm{CT})$}

A total of six cylindrical core samples ( $\mathrm{L}=3$ inches $\times \mathrm{D}=1.5$ inches) were used in the study. Three samples were shale, denoted with $\left(\mathrm{Sh}_{1}\right.$, $\mathrm{Sh}_{2}$ and $\left.\mathrm{Sh}_{3}\right)$, and three samples were sandstone, denoted with $\left(\mathrm{S}_{1}, \mathrm{~S}_{2}\right.$, and $\mathrm{S}_{3}$ ). The shale core samples were extracted from the Eagle Ford Shale Formation, whereas the sandstone samples were extracted from the Gray Berea Formation. CT scanning was conducted before and after the hydraulic fracturing procedure to account for the existence of natural fractures within the samples. Hydraulic fracturing was conducted using a compressive strength machine at the Department of Civil Engineering of Texas Tech University, which can be seen (Figure 1). A triaxial hydraulic fracturing system would be more effective at imitating the in-situ stress conditions. Unfortunately, it was difficult to use in this case due to the small sample size. Therefore, a regular concrete compressive strength machine was used for the hydraulic fracturing. The load used in fracturing the shale and sandstone samples remained the same for the three samples from each type. This was done to eliminate the consideration of load from the comparison between the

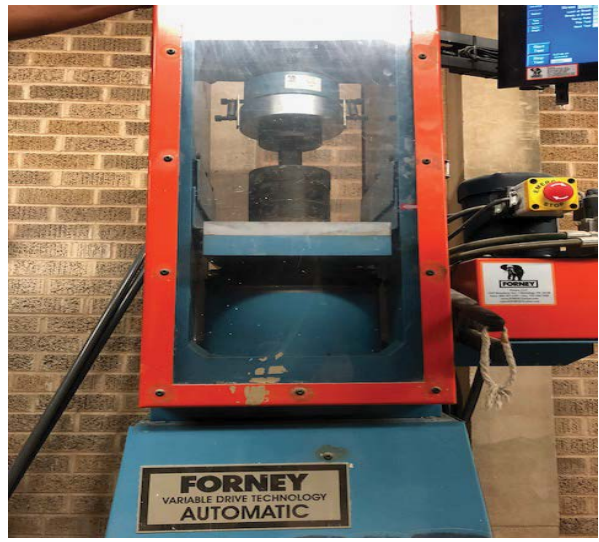

Figure 1: Compressive strength machine used in fracturing the samples. 
two different lithologies. A load of (120 lbf) was used in the hydraulic fracturing of sandstone samples, and a load of $(720 \mathrm{lbf})$ was used in the hydraulic fracturing of shale samples.

The samples were scanned at a computer tomography facility in the petroleum engineering department, Texas Tech University (TTU). Ketcham and Carlson provided a detailed explanation of the scanning process and different applications of X-ray computed tomography in the geosciences [13]. The samples were scanned using a Neurologica CereTom instrument (NL 3000 model) which is an 8 slice, small bore, portable CT scanner. CT scanning machines consist of a table, a rotating $\mathrm{X}$-ray tube mounted inside a gantry, and an X-ray beam detector placed at the opposite side of the X-ray source. First, the sample is fixed in a horizontal position inside a plastic tube. This prevents the sample from moving during the scan. Then the sample is placed inside the instrument over the moving table, which moves the sample while it is bombarded with a continuous $\mathrm{x}$-ray beam. The detector captures the X-ray beam after it passes through the sample. The samples were scanned using an $\mathrm{X}$-ray source of $140 \mathrm{KV}$ and current of $7 \mathrm{~mA}$. The system generates up to 8 slices (image) per revolution and the data is captured and digitalized by a Modular Multi-Row Detector (MMD). The system produces an image every 22.5 degrees, or every $1.25 \mathrm{~mm}$ (slice thickness) with a total of 8 frames within $180^{\circ} \mathrm{C}$ of rotation. Image-J free open source software was then used for performing the quantitative analysis of the $2 \mathrm{D}$ images. CT scanning quantitative analysis is crucial in data image processing. This is done by reconstructing a $3 \mathrm{D}$ volume rendering from the $\mathrm{CT}$ scans, $2 \mathrm{D}$ images. $3 \mathrm{D}$ image reconstruction allows one to study and visualize the internal structure of an object in a nondestructive way. The purpose of 3D and multi-planer reconstruction (MPR) images in our study is to measure the height and the aperture of hydraulic fractures, and to visualize the fracture networks in 3D. Image segmentation, which is the process of isolating the fracture network from the rock matrix, is the first step in creating $3 \mathrm{D}$ volume renderings. Selecting the threshold for segmentation is considered very important in data processing. There are three different methods in selecting the thresholding value. They are manual selection by the user, automatic selection based on thresholding algorithm, and mean value selection. The visual interpretation threshold method, which is the most common thresholding technique used in geosciences applications, was used in this research [16]. Visual interpretation was used since distinguishing between the fracture networks and the rock matrix is easy. This is due to gray-scale voxel values for the fractures being lower than the gray-scale voxel values of the matrix. The detailed explanations for segmentation and the different thresholding methods in Raju et al. [17].

\section{$\mathrm{X}$-ray powder diffraction $(\mathrm{XRD})$}

Semi-quantitative whole-rock XRD analysis was carried out on all 6 samples for mineralogical investigation. A small slice sample was extracted from each core. This was then gently crushed and powdered using a rock crusher and shatter box. The resulting powder was placed into a 1.5" backfill standard sample holder for XRD analysis. All samples were scanned with a continuous time of 10 s per $0.05^{\circ} 2 \Theta$ over the range of 2 to $72^{\circ} 2 \Theta\left(\mathrm{U}=30 \mathrm{kV}, \mathrm{I}=15 \mathrm{~mA} ; \mathrm{CuK}_{\alpha}\right.$ radiation $)$ using a Rigaku Miniflex II installed at the Department of Geosciences (Texas Tech University, USA). Interpretation of the XRD pattern for Phase identification was conducted using the Rigaku PDXL Integrated X-ray powder diffraction software (v. 2.7.2.0). Phase identification was done by comparing the experimental peaks with the published files provided by the International Centre for Diffraction Data (JCPDS 2000).

\section{$\mathrm{X}$-ray fluorescence (XRF)}

XRF analysis was performed on a total of 6 samples for whole-rock element quantification using a Thermo Scientific ARL PERFORM'X Sequential X-Ray Fluorescence Spectrometer combined with proprietary Uniquant software at the Department of Geosciences (Texas Tech University, USA). Approximately $4 \mathrm{~g}$ of rock powder was placed into a porcelain crucible which was then placed into a muffle furnace at $1000^{\circ} \mathrm{C}$ for 30 minutes to prepare the sample for a loss on ignition (LOI) analysis. An LOI sample of $1.2000 \mathrm{~g} \pm 0.0010 \mathrm{~g}$ was mixed with 4.8000 $\mathrm{g} \pm 0.0020 \mathrm{~g}$ of a $49.75 \%$ Li-metaborate, $49.75 \%$ of Li-tetraborate, and $0.5 \% \mathrm{LiBr}$ fluxing agent. The mix was used to prepare a glass disc for the sample for XRF analysis [18]. The mixture then was mixed with $40 \mu \mathrm{L}$ of a LiI (wetting agent) and then fused using M4 fluxer.

\section{Porosity and permeability}

Sandstone porosity values were obtained from the core sample company (Kocurek Industries, INC, USA) (Table 1). The sandstone sample permeability was measured at the Department of Petroleum Engineering of Texas Tech University. Permeability was measured by applying Darcy's law for each sample using gas, the steps used to take the measurements is below.

1. Air was available in the laboratory to use at the inlet $\left(\mathrm{P}_{1}\right)$, and the outlet gas pressure was constant, $\mathrm{P}_{0}=1$ atm $(14.7 \mathrm{psi})$.

2. Five different pressure values were chosen for each sample.

3. The flow rate for each pressure and sample was measured using a flow-meter.

\section{The viscosity of air is constant $(0.01827 \mathrm{Cp})$.}

Using the steps above, effective permeability of the sandstone samples was calculated at five different pressures for each sample. Average permeability was calculated for each sample using the arithmetic averages law (total of effective permeabilities/number of experiments). For more details, an in-depth explanation can be obtained from [19]. Shale sample porosity values were measured in the laboratory using a porosimeter. The test used Helium to calculate the porosity of the samples based on Boyle's law. The permeabilities of the shale samples were measured in the laboratory using AutoLab 1500. The description of the methods used to measure shale permeability can be found in (AutoLab 1500 - New England Research/NER) [20].

\begin{tabular}{|c|c|c|c|c|c|c|}
\hline \multicolumn{2}{|c|}{ Sample Name } & Porosity (Фe), \% & Per., $\mu \mathrm{D}$ & Dry bulk Den., gr/cc & Young's Modulus, Gpa & Poisson's ratio \\
\hline \multirow{3}{*}{ Shale } & $\mathrm{Sh}_{1}$ & 2.262 & 0.0402 & 2.588 & 27.6 & 0.23 \\
\hline & $\mathrm{Sh}_{2}$ & 1.760 & 0.00307 & 2.431 & 20.7 & 0.24 \\
\hline & $\mathrm{Sh}_{3}$ & 6.782 & 492.00 & 2.225 & 34.5 & 0.26 \\
\hline \multirow{3}{*}{ Sandstone } & $\mathrm{S}_{1}$ & 20.00 & 67204 & 1.612 & 20 & 0.24 \\
\hline & $\mathrm{S}_{2}$ & 20.00 & 38321 & 2.123 & 17 & 0.26 \\
\hline & $\mathrm{S}_{3}$ & 19.00 & 34017 & 2.121 & 17 & 0.28 \\
\hline
\end{tabular}

Table 1: Porosity, permeability, dry bulk density, Young's modules, and poison ratio results for tested shale and sandstone samples. 
Citation: Susi AO, Mahrous MA, Elwegaa KA, Sims PL, Heinz IR, et al. (2018) Optimization of Composite Layering Effect Based on Measured Formation Fracture Height to Length Ratios. J Pet Environ Biotechnol 9: 376. doi: 10.4172/2157-7463.1000376

\section{Results and Discussion}

\section{Composite layering effect analysis (CLE)}

CLE values were calculated using the following two equations, which were obtained from [11].

$$
\mathrm{I}=\frac{\mathrm{H}}{\mathrm{L}} \quad \text { (1) } \mathrm{X}=10^{\mathrm{c}}
$$

Where;

$$
\mathrm{C}=\frac{\log _{10}^{\mathrm{I}}-\log _{10}^{\mathrm{a}}}{\mathrm{b}}
$$

I=Height to length ratio, $\mathrm{X}=\mathrm{CLE}$ Value, $\mathrm{a}=0.9978$ constant (Intercept), $\mathrm{b} \mu=0.4349$ constant (slope).

Calculating CLE values starts by calculating the height to length ratio (I) of the hydraulic fractures from the CT scan's MPR images using equation (1) and substituting the obtained value of (I) in equation (2). The following example is for demonstration purposes, showing the steps of calculating the CLE value of a sandstone sample $\left(\mathrm{S}_{1}\right)$ from CT scan images. First, MPR images for the XZ direction were developed from the $2 \mathrm{D}$ axial view images using Image-J software (Figure 2). Second, the height and the length of the selected fracture was measured and the ratio was calculated between them (I). The obtained value was then substituted in equation (2) to measure the CLE value of each sample. Note that in the case of more than one fracture existing in a sample, CLE values were calculated for each fracture separately and averaged to provide a general CLE value for the whole sample. Since the samples are not homogenous materials, using the average CLE value is acceptable. Similarly, CLE values were obtained for all other samples using the previously described method. A summary of the calculated results for all samples (Table 2). Note that the calculated average CLE value was divided by 100 to obtain CLE values ranging from 1 to 100 similar to the CLE values obtained from FracPro software described in detail by Susi et al. [11].

A summary of XRD and XRF measurements conducted on the shale and sandstone samples is shown in Table 3 and Table 4 respectively. The XRD analysis shows that the sandstone samples have very similar quartz values of $84.4 \%, 86.6 \%$, and $86.1 \%$ corresponding to $S_{1}, S_{2}$, and $S_{3}$ respectively (Table 3 ). Similarly, clay mineral dickite measured $2 \%, 2.1 \%$, and $2 \%$ corresponding to $\mathrm{S}_{1}, \mathrm{~S}_{2}$, and $\mathrm{S}_{3}$ respectively. Mineral orthoclase measured in $S_{1}$ slightly higher than $S_{2}$ and $S_{3}$ with value of $9.6 \%$ for $S_{1}$ and $7.5 \%$ and $7.7 \%$ for $S_{2}$ and $S_{3}$ respectively.
Generally, it was noticed that all sandstone samples are mineralogically similar with slight differences in quartz, orthoclase and clay minerals. Therefore, sandstone samples are siliceous mudstone and can probably be classified as arenites. Furthermore, for the shale samples, quartz constituents steadily increased, starting with $4.6 \%$ for $\mathrm{Sh}_{1}$, increasing to $15.6 \%$ for $\mathrm{Sh}_{2}$ and reaching $20.7 \%$ for $\mathrm{Sh}_{3}$. The first observation based on shale XRD measurements point to a clear increase in calcite constituents and a strong reduction in clay content, with values of $91.6 \%, 80.8 \%$ and $75.2 \%$ for $\mathrm{Sh}_{1}, \mathrm{Sh}_{2}$, and $\mathrm{Sh}_{3}$ respectively. It was noticed that the clay mineral (nacrite) component is significantly lower than expected for the shale formation, which reported values of $2.6 \%, 2.7 \%$, and $3.4 \%$ corresponding to $\mathrm{Sh}_{1}, \mathrm{Sh}_{2}$, and $\mathrm{Sh}_{3}$ respectively. XRF analysis for the shale samples also showed a significant increase in $\mathrm{CaO}$ and $\mathrm{SiO}_{2}$ concentration (Table 4). This phenomenon can be attributed to the fact that the shale samples are extracted from a shale oil formation. It is known that common shale formations generally contain an average of $60 \%$ clay minerals, whereas shale oil formations can consist of as high as $30 \%$ clay minerals and mainly consist of calcite [21]. A similar observation was documented by Emadibaladehi, reporting that mineralogical analysis from shale cores extracted from the shale oil Eagle Ford Formation measured calcite percentages as high as 55\% and $53 \%$ and clay minerals of $27 \%$ and $8 \%$ in two different cores [21]. The difference in the XRD analysis results in the same formation is caused by the inhomogeneous nature of the formation due to the depositional environment changes. Mineralogical and chemical analysis of shale samples shows that the most abundant mineral is calcite, which implies that shale samples can be classified as carbonate mudstone.

\section{Analysis of CLE and the sample mineralogy relationship}

CLE values For $\mathrm{S}_{1}, \mathrm{~S}_{2}$, and $\mathrm{S}_{3}$ are 2.20, 8.43, and 7.54 corresponding to quartz concentration of $84.4 \%, 86.6 \%$, and $86.1 \%$. The relationship between the CLE values and quartz concentration for the sandstone samples showed that the CLE values increased with an increase of quartz content (Figure 3). The brittle behaviors of a rock are controlled by several factors such as in-situ stress, mineralogical composition, and moisture content. This makes it quite difficult to evaluate brittleness [22]. Therefore, the dramatic changes in CLE values could be due to an increase in rock brittleness resulting from the slight growth of quartz concentration.

CLE values show a strong relationship with changes in concentration of quartz, calcite, and clay mineral (nacrite). It was observed that CLE values for $\mathrm{Sh}_{1}, \mathrm{Sh}_{2}$, and $\mathrm{Sh}_{3}$ measured 11, 17, and 43 respectively, while
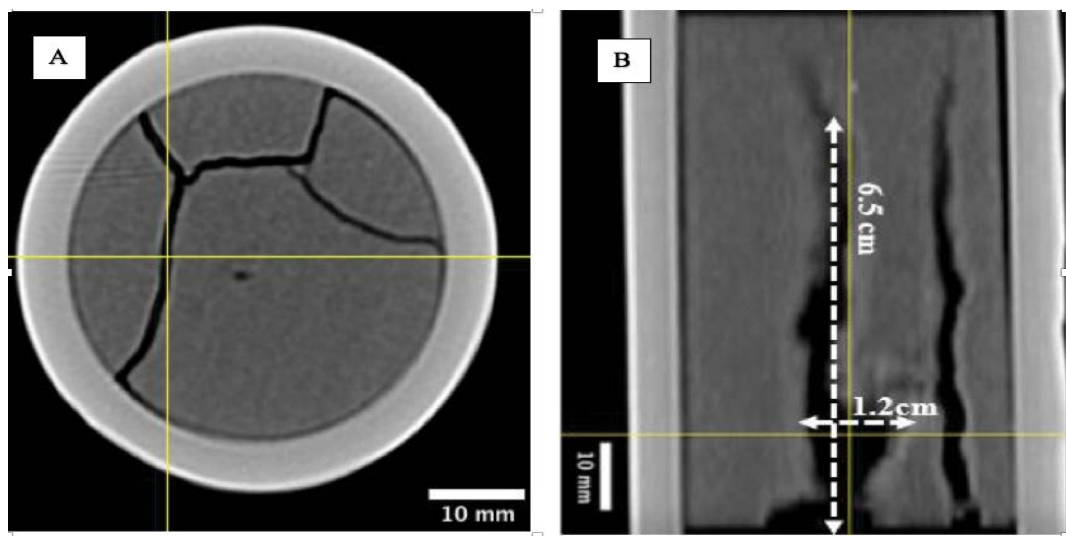

Figure 2: (A) 2D image axial view for $S_{1}$; (B) MPR image (XZ) for the selected fracture using the yellow lines in (A) 
Citation: Susi AO, Mahrous MA, Elwegaa KA, Sims PL, Heinz IR, et al. (2018) Optimization of Composite Layering Effect Based on Measured Formation Fracture Height to Length Ratios. J Pet Environ Biotechnol 9: 376. doi: 10.4172/2157-7463.1000376

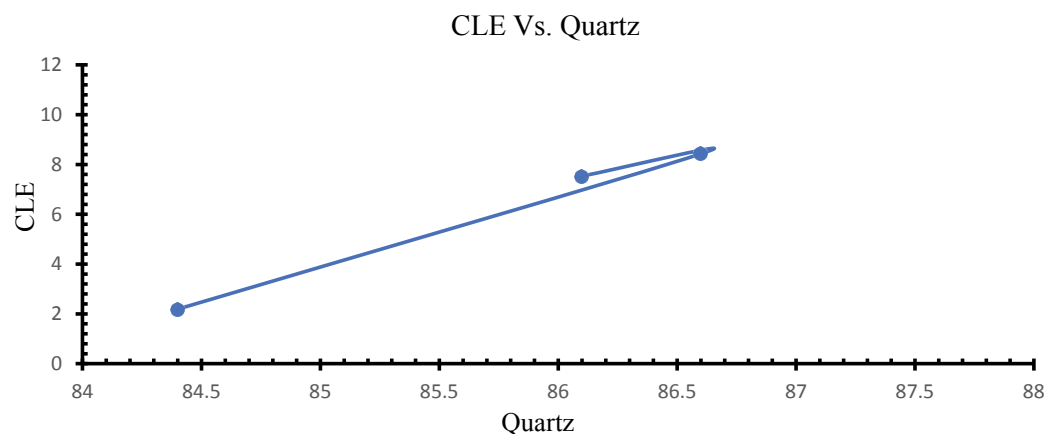

Figure 3: CLE values versus quartz content for sandstone samples.

CLE Vs. Clay

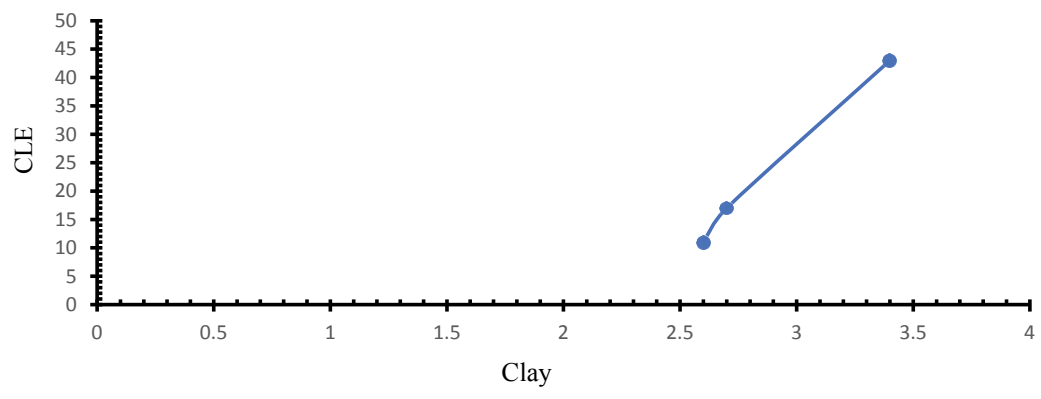

Figure 4: CLE values versus clay minerals (nacrite) content for shale samples.

\begin{tabular}{|c|c|c|c|c|c|c|}
\hline Sample No. & $\mathrm{H}, \mathrm{cm}$ & $\mathrm{L}, \mathrm{cm}$ & I & CLE & CLE avg. & CLE/100 \\
\hline \multirow{2}{*}{$S_{1}$} & 6.5 & 1.2 & 5.420 & 48.68000 & \multirow{2}{*}{219.70} & \multirow{2}{*}{2.20} \\
\hline & 6.7 & 0.5 & 13.40 & 390.7200 & & \\
\hline \multirow{2}{*}{$\mathrm{S}_{2}$} & 5.0 & 0.4 & 12.50 & 332.9900 & \multirow{2}{*}{843.07} & \multirow[b]{2}{*}{8.43} \\
\hline & 4.6 & 0.2 & 23.00 & 1353.160 & & \\
\hline \multirow{2}{*}{$\mathrm{S}_{3}$} & 4.8 & 0.2 & 24.00 & 1492.280 & \multirow{2}{*}{753.51} & \multirow[b]{2}{*}{7.54} \\
\hline & 2.9 & 0.9 & 3.220 & 14.75000 & & \\
\hline $\mathrm{Sh}_{1}$ & 6.3 & 0.3 & 21.00 & 1097.750 & -- & 10.98 \\
\hline $\mathrm{Sh}_{2}$ & 7.6 & 0.3 & 25.33 & 1689.820 & -- & 16.90 \\
\hline $\mathrm{Sh}_{3}$ & 7.6 & 0.2 & 38.00 & 4292.810 & -- & 42.93 \\
\hline
\end{tabular}

Table 2: Reported CLE values for sandstone and shale samples.

the clay content (nacrite) shows a gradual increase from $2.6 \%$ for $\mathrm{Sh}_{1}$ to $2.7 \%$ for $\mathrm{Sh}_{2}$ and recorded the maximum CLE value at $3.4 \%$ nacrite mineral (Figure 4). Although the amount of clay minerals present is not significant, it caused a dramatic increase in the CLE value. This is due to an improvement of the ductile behaviors of the rock formation and the reduction in overall rock brittleness Therefore, it is clear that the presence of considerable amounts of clay mineral in a rock formation will result in difficulties implementing a hydraulic fracking treatment $[23,24]$.

Furthermore, CLE values decreased as the calcite mineral content increased. CLE values measured 11, 17, and 43 corresponding to calcite concentrations of $91.6 \%\left(\mathrm{Sh}_{1}\right), 80.8 \%\left(\mathrm{Sh}_{2}\right)$, and $75.2 \%\left(\mathrm{Sh}_{3}\right)$ respectively (Figure 5). Also, it was noticed that CLE values increased as quartz minerals increased. $\mathrm{Sh}_{1}$ had $4.6 \%$ quartz corresponding to a CLE value of $11, \mathrm{Sh}_{2}$ had $15.6 \%$ quartz corresponding to a CLE value of $17, \mathrm{Sh}_{3}$ had $20.7 \%$ quartz corresponding to a CLE value of 43 (Figure 6). The increase in quartz concentration should result in a reduction in CLE value, but this did not happen in our case. This could be explained by the presence of preexisting fractures (PEF) sealed with calcite which were observed by CT scan images taken prior to the fracking procedure for shale sample $\mathrm{Sh}_{3}$ (Figure 7). However, Martineau concluded that limestone $\left(\mathrm{CaCO}_{3}\right)$ generally has a higher fracture threshold than the shale itself. This provides a barrier against stimulating fracturing in shale formations [25]. Therefore, the reduction on the CLE value as the calcite minerals increased could be due to the brittleness behavior of the calcite which reduced the ductility properties of clay minerals which are resulted in reduction on the ability of the rock to absorb more forces prior to fracturing. The growth of the CLE value in $\mathrm{Sh}_{3}$ could be attributed to greater clay content. Therefore, CLE value is mainly affected by three major minerals (quartz, calcite, and clay minerals) and the presence of preexisting fractures.

\section{$\mathrm{X}$-ray computed tomography $(\mathrm{CT})$}

Pre-fracking and post-fracking CT scanning was performed to investigate the presence of preexisting fractures. It was found that shale sample $\mathrm{Sh}_{3}$ had a preexisting fracture which could be either a natural fracture or a fracture induced during the coring process (Figure 7). The hydraulically induced fractures in the 2D CT scan images of the sandstone samples were found to be concentrated in the bottom part of 
Citation: Susi AO, Mahrous MA, Elwegaa KA, Sims PL, Heinz IR, et al. (2018) Optimization of Composite Layering Effect Based on Measured Formation Fracture Height to Length Ratios. J Pet Environ Biotechnol 9: 376. doi: 10.4172/2157-7463.1000376

Page 6 of 11

\begin{tabular}{|c|c|c|}
\hline \multicolumn{2}{|r|}{ Phase } & \multirow{2}{*}{$\begin{array}{c}\text { Wt, \% } \\
84.4\end{array}$} \\
\hline \multirow{5}{*}{$\mathrm{S}_{1}$} & Quartz low $-\mathrm{SiO}_{2}$ & \\
\hline & Dickite $2 \mathrm{M}_{1}-\mathrm{Al}_{2} \mathrm{Si}_{2} \mathrm{O}_{5}(\mathrm{OH})_{4}$ & 2.00 \\
\hline & Orthoclase $-\mathrm{K}\left(\mathrm{AISi}_{3} \mathrm{O}_{8}\right)$ & 9.60 \\
\hline & Phlogopite $1 \mathrm{M}-\mathrm{KMg}_{2} \cdot 75 \mathrm{Si}_{3} \cdot 5 \mathrm{Al0} .5 \mathrm{O}_{10} \mathrm{~F}_{2}$ & 1.00 \\
\hline & Phengite $2 \mathrm{M} 1$ - $(\mathrm{K} 0.95 \mathrm{Na} 0.05)(\mathrm{Al} 0.76 \mathrm{Fe} 0.14 \mathrm{Mg} 0.10) 2(\mathrm{Si} 3.25 \mathrm{Al} 0.75) \mathrm{O}_{10}$ & 3.00 \\
\hline \multirow{5}{*}{$\mathrm{S}_{2}$} & Quartz low $-\mathrm{SiO}_{2}$ & 86.6 \\
\hline & Dickite $2 \mathrm{M}_{1}-\mathrm{Al}_{2} \mathrm{Si}_{2} \mathrm{O}_{5}(\mathrm{OH})_{4}$ & 2.10 \\
\hline & Orthoclase - $\mathrm{K}\left(\mathrm{AlSi}_{3} \mathrm{O}_{8}\right)$ & 7.50 \\
\hline & Phlogopite $1 \mathrm{M}-\mathrm{KMg}^{2} .75 \mathrm{Si} 3.5 \mathrm{Al0} .5 \mathrm{O}_{10} \mathrm{~F}_{2}$ & 0.90 \\
\hline & Phengite $2 \mathrm{M}_{1}-(\mathrm{K} 0.95 \mathrm{Na} 0.05)(\mathrm{Al} 0.76 \mathrm{Fe} 0.14 \mathrm{Mg} 0.10) 2\left(\mathrm{Si}_{3} .25 \mathrm{Al} 0.75\right) \mathrm{O}_{10}$ & 2.90 \\
\hline \multirow{5}{*}{$\mathrm{S}_{3}$} & Quartz low $-\mathrm{SiO}_{2}$ & 86.1 \\
\hline & Dickite $2 \mathrm{M} 1-\mathrm{Al}_{2} \mathrm{Si}_{2} \mathrm{O}_{5}(\mathrm{OH})_{4}$ & 2.00 \\
\hline & Orthoclase $-\mathrm{K}\left(\mathrm{AlSi}_{3} \mathrm{O}_{8}\right)$ & 7.70 \\
\hline & Phlogopite $1 \mathrm{M}-\mathrm{KMg}_{2} \cdot 7_{5} \mathrm{Si}_{3} \cdot 5 \mathrm{Al}_{0} .5 \mathrm{O}_{10} \mathrm{~F}_{2}$ & 2.40 \\
\hline & Phengite $2 \mathrm{M} 1$ - $(\mathrm{K} 0.95 \mathrm{Na} 0.05)(\mathrm{Al} 0.76 \mathrm{Fe} 0.14 \mathrm{Mg} 0.10) 2(\mathrm{Si} 3.25 \mathrm{Al} 0.75) \mathrm{O}_{10}$ & 1.90 \\
\hline \multirow{5}{*}{$\mathrm{Sh}_{1}$} & Calcite $-\mathrm{Ca}\left(\mathrm{CO}_{3}\right)$ & 26.2 \\
\hline & Quartz low - $\mathrm{SiO}_{2}$ & 4.60 \\
\hline & Boehmite - $\mathrm{AlO}(\mathrm{OH})$ & 1.30 \\
\hline & Calcite $-\mathrm{CaCO}_{3}$ & 65.4 \\
\hline & Nacrite $-\mathrm{Al}_{2} \mathrm{Si}_{2} \mathrm{O}_{5}(\mathrm{OH})_{4}$ & 2.60 \\
\hline \multirow{6}{*}{$\mathrm{Sh}_{2}$} & Calcite - $\mathrm{Ca}\left(\mathrm{CO}_{3}\right)$ & 26.9 \\
\hline & Quartz low $-\mathrm{SiO}_{2}$ & 15.6 \\
\hline & Boehmite - $\mathrm{AlO}(\mathrm{OH})$ & 0.70 \\
\hline & Calcite $-\mathrm{CaCO}_{3}$ & 53.9 \\
\hline & Nacrite $-\mathrm{Al}_{2} \mathrm{Si}_{2} \mathrm{O}_{5}(\mathrm{OH})_{4}$ & 2.70 \\
\hline & Tausonite $\left(\mathrm{Ca}-\left(\mathrm{Ca} 0.35 \mathrm{Sr}_{0.65}\right)\left(\mathrm{TiO}_{3}\right)\right.$ & 0.20 \\
\hline \multirow{5}{*}{$\mathrm{Sh}_{3}$} & Calcite $-\mathrm{Ca}\left(\mathrm{CO}_{3}\right)$ & 19.4 \\
\hline & Quartz low - $\mathrm{SiO}_{2}$ & 20.7 \\
\hline & Boehmite - $\mathrm{AlO}(\mathrm{OH})$ & 0.70 \\
\hline & Calcite $-\mathrm{CaCO}_{3}$ & 55.8 \\
\hline & Nacrite $-\mathrm{Al}_{2} \mathrm{Si} 2 \mathrm{O}_{5}(\mathrm{OH})_{4}$ & 3.40 \\
\hline
\end{tabular}

Table 3: XRD measurements results for the shale and sandstone samples.

\begin{tabular}{|c|c|c|c|c|c|c|}
\hline Wt.\% & $\mathbf{S}_{1}$ & $\mathbf{S}_{2}$ & $\mathrm{~S}_{3}$ & $\mathrm{Sh}_{1}$ & $\mathrm{Sh}_{2}$ & $\mathrm{Sh}_{3}$ \\
\hline $\mathrm{CaO}$ & 0.2224 & 0.213 & 0.2065 & 77.9102 & 60.3196 & 53.0159 \\
\hline $\mathrm{SiO}_{2}$ & 89.7849 & 89.908 & 89.1752 & 20.1656 & 35.1231 & 42.6898 \\
\hline $\mathrm{TiO}_{2}$ & 0.3943 & 0.3953 & 0.3932 & 0.0496 & 0.1061 & 0.09490 \\
\hline $\mathrm{Al}_{2} \mathrm{O}_{3}$ & 4.2148 & 4.2059 & 4.1859 & 2.8972 & 3.6049 & 3.63110 \\
\hline $\mathrm{Fe}_{2} \mathrm{O}_{3}$ & 0.7629 & 0.7473 & 0.761 & -0.2347 & 0.2522 & 0.55350 \\
\hline $\mathrm{MgO}$ & 0.4112 & 0.4049 & 0.4038 & 0.7902 & 1.1634 & 0.52340 \\
\hline $\mathrm{MnO}$ & 0.017 & 0.0162 & 0.0167 & 0.0222 & 0.0104 & 0.00550 \\
\hline $\mathrm{Na}_{2} \mathrm{O}$ & 0.2976 & 0.3198 & 0.3149 & 0.0954 & 0.0971 & 0.19280 \\
\hline $\mathrm{K}_{2} \mathrm{O}$ & 1.181 & 1.1637 & 1.144 & 0.0293 & 0.2779 & 0.17680 \\
\hline $\mathrm{P}_{2} \mathrm{O}_{5}$ & 0.027 & 0.027 & 0.026 & 0.0887 & 0.125 & 0.09260 \\
\hline LOI & 1.66 & 1.59 & 1.6 & -- & -- & -- \\
\hline Sum & 98.9731 & 98.9911 & 98.2272 & 101.8223 & 101.0857 & 100.982 \\
\hline
\end{tabular}

Table 4: XRF measurements results for the shale and sandstone samples.

the samples, which was observed in the axial cross-section $2 \mathrm{D}$ images (Figure 8). Sandstone samples $\mathrm{S}_{1}$ and $\mathrm{S}_{2}$ exhibited similar fracture geometry which formed a fracture network starting in the middle of the sample and propagating toward the edge of the core. $S_{3}$ exhibited different fracture geometry, formed by one large crack intersected with a smaller one close to the edge of the core sample (Figure 8). It was also noticed that the fracture apparatus for most of the induced fractures gradually decreased in width from the bottom of the sample toward to the top. This observation indicates that the fracture started at the bottom of the sample and propagated through the sample perpendicular to the applied force. This was perfectly visualized in Multi-planar reconstructed images (MPR) (Figure 9). Furthermore, the induced 
Citation: Susi AO, Mahrous MA, Elwegaa KA, Sims PL, Heinz IR, et al. (2018) Optimization of Composite Layering Effect Based on Measured Formation Fracture Height to Length Ratios. J Pet Environ Biotechnol 9: 376. doi: 10.4172/2157-7463.1000376

\section{CLE Vs. Calcite}

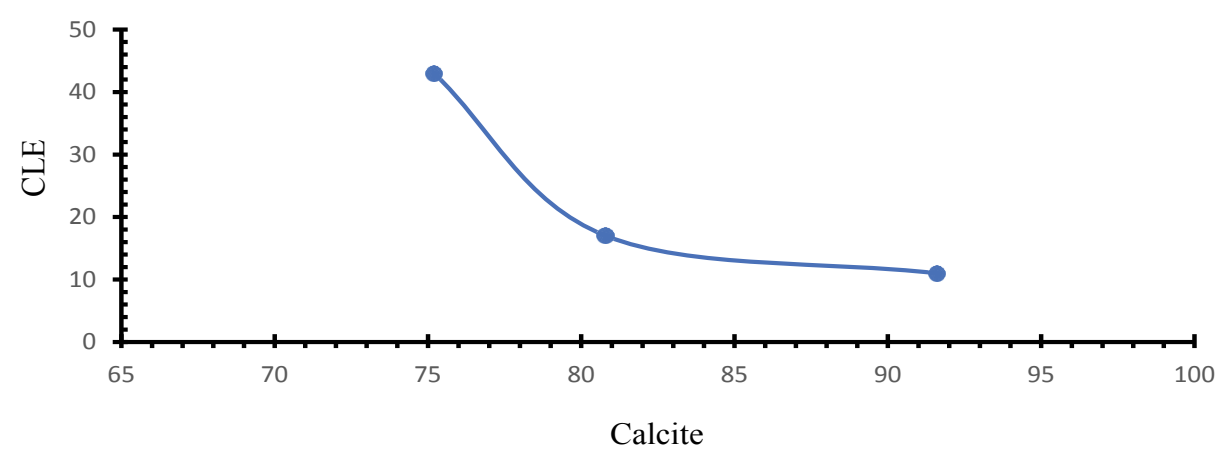

Figure 5: CLE values versus calcite minerals content for shale samples.

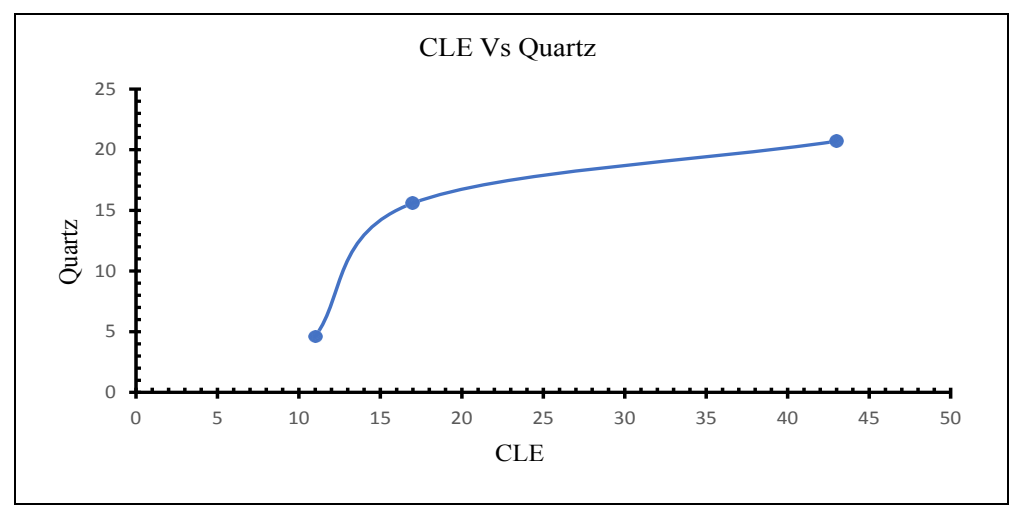

Figure 6: CLE values versus calcite minerals content for shale samples.
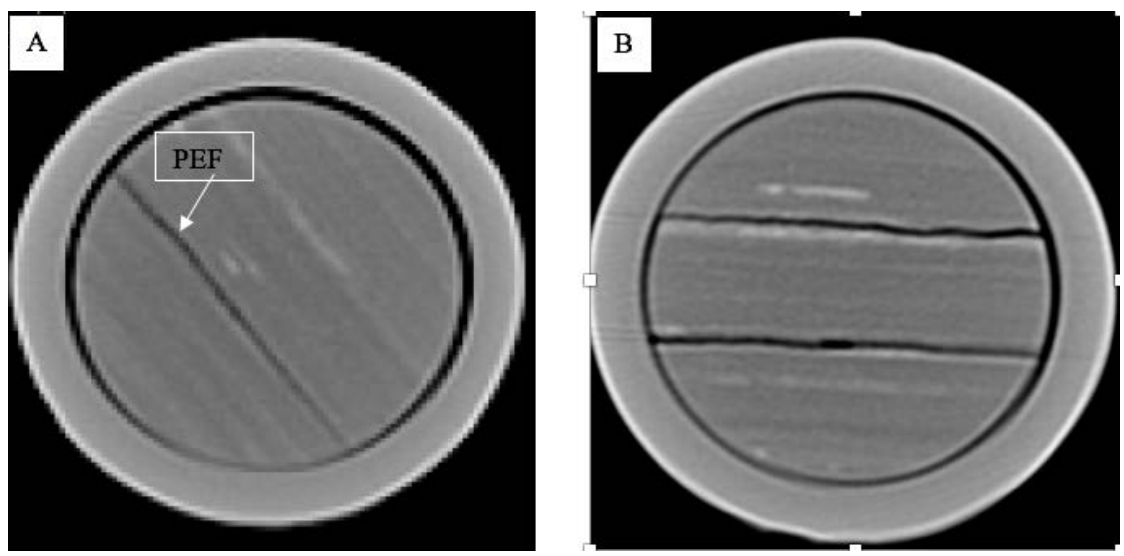

Figure 7: 2D CT scanning images for shale sample $\mathrm{Sh}_{3}(\mathrm{~A})$ The image before fracturing $(\mathrm{B})$ The image after fracturing. [Abbreviation: PEF: Preexisting Fracture]

fractures propagate through brighter parts of the rock matrix (Figure 9). Since areas of higher density appear brighter than low density, this implies that the fractures propagated through higher density regions. In the images, fractures appear the darkest as they contain air, which has low density comparatively. MPR and 3D reconstructed images for sandstone samples show that all three samples exhibit more than one fracture that start parallel to one another and then connect to form a fracture network (Figures 9 and 10). Similarly, shale samples show that cracks also propagated through high-density areas, implying that propagation occurs in high quartz concentrations (Figures 11 and 12).
Figures $11 \mathrm{c}$ and $12 \mathrm{~d}$ showed that the crack started as a straight line and then bent to follow the area with high density (brighter parts). It was observed that the induced fractures in shale samples were mainly parallel to each other, and they didn't form fracture networks as in sandstone samples. This could be attributed to shale's low permeability and higher clay mineral concentrations which makes the rock less brittle and exhibits more ductile behavior. Moreover, the induced cracks in the shale samples had constant fracture apparatuses through the entire sample. This could be due to the higher percentage of $\mathrm{CaCO}_{3}$ which was observed by XRD analysis, because calcite works as a barrier 
Citation: Susi AO, Mahrous MA, Elwegaa KA, Sims PL, Heinz IR, et al. (2018) Optimization of Composite Layering Effect Based on Measured Formation Fracture Height to Length Ratios. J Pet Environ Biotechnol 9: 376. doi: 10.4172/2157-7463.1000376

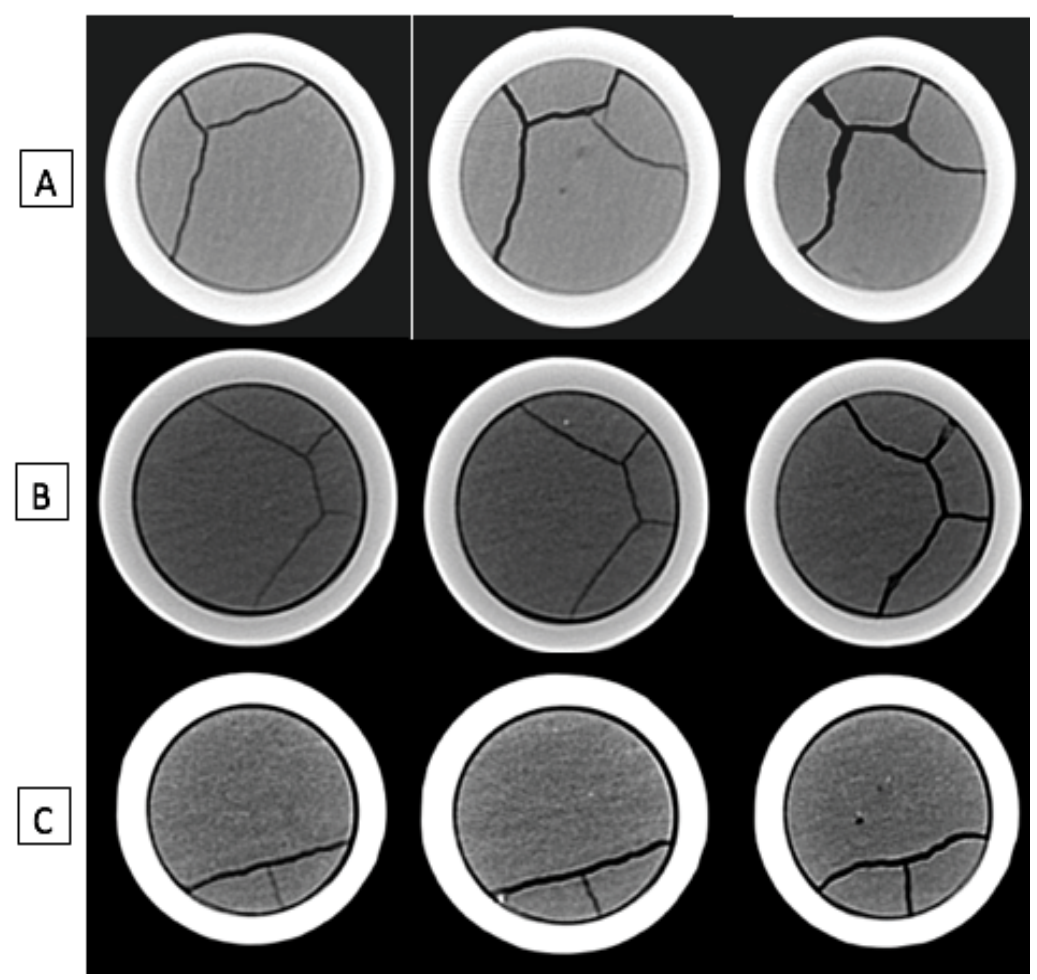

Figure 8: CT scan 2D images for sandstone samples: A, B, and C are corresponding to $\mathrm{S} 1, \mathrm{~S} 2$, and $\mathrm{S} 3$ respectively.

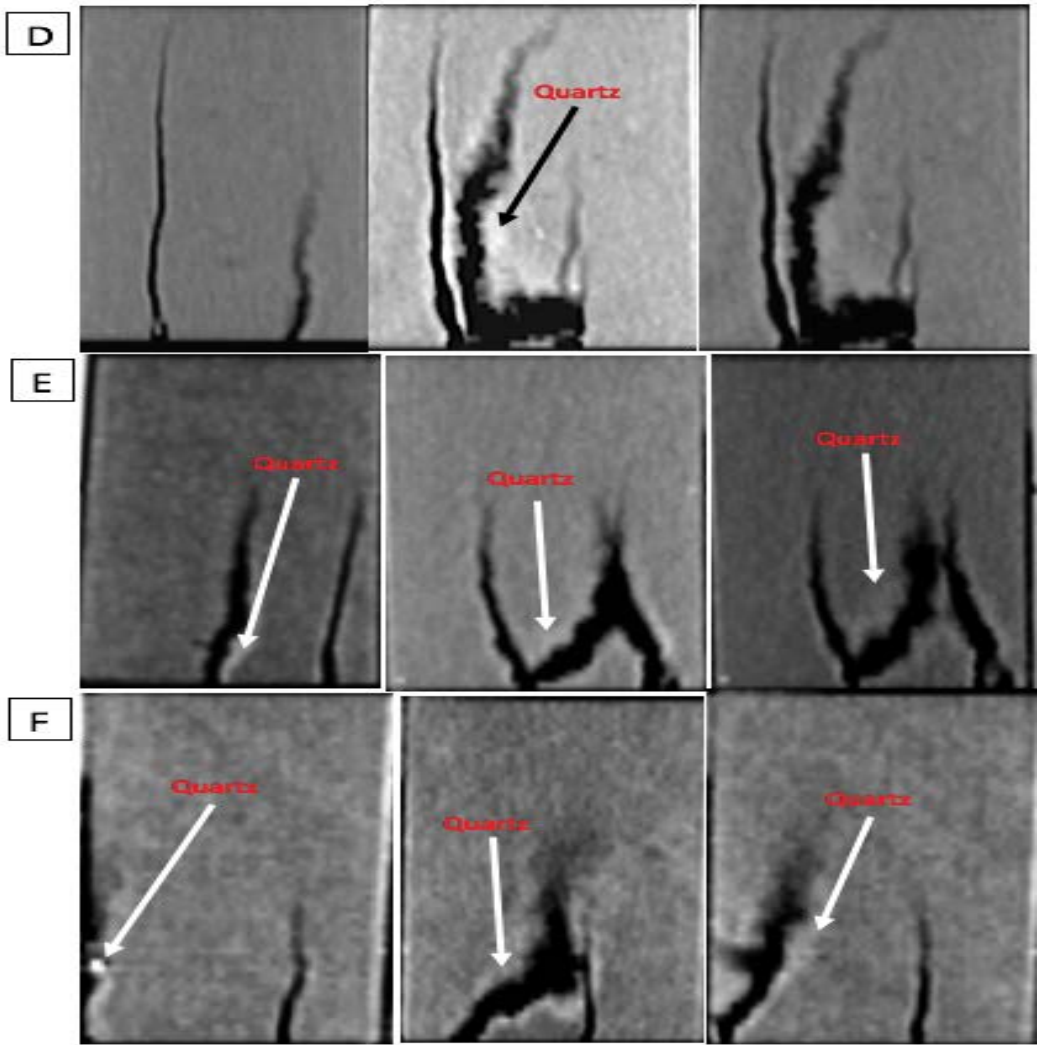

Figure 9: Multiplanar reconstruction (MPR) images XZ view for sandstone samples. D, E, and $F$ correspond to $S_{1}, S_{2}$, and $S_{3}$ respectively. 
Citation: Susi AO, Mahrous MA, Elwegaa KA, Sims PL, Heinz IR, et al. (2018) Optimization of Composite Layering Effect Based on Measured Formation Fracture Height to Length Ratios. J Pet Environ Biotechnol 9: 376. doi: 10.4172/2157-7463.1000376

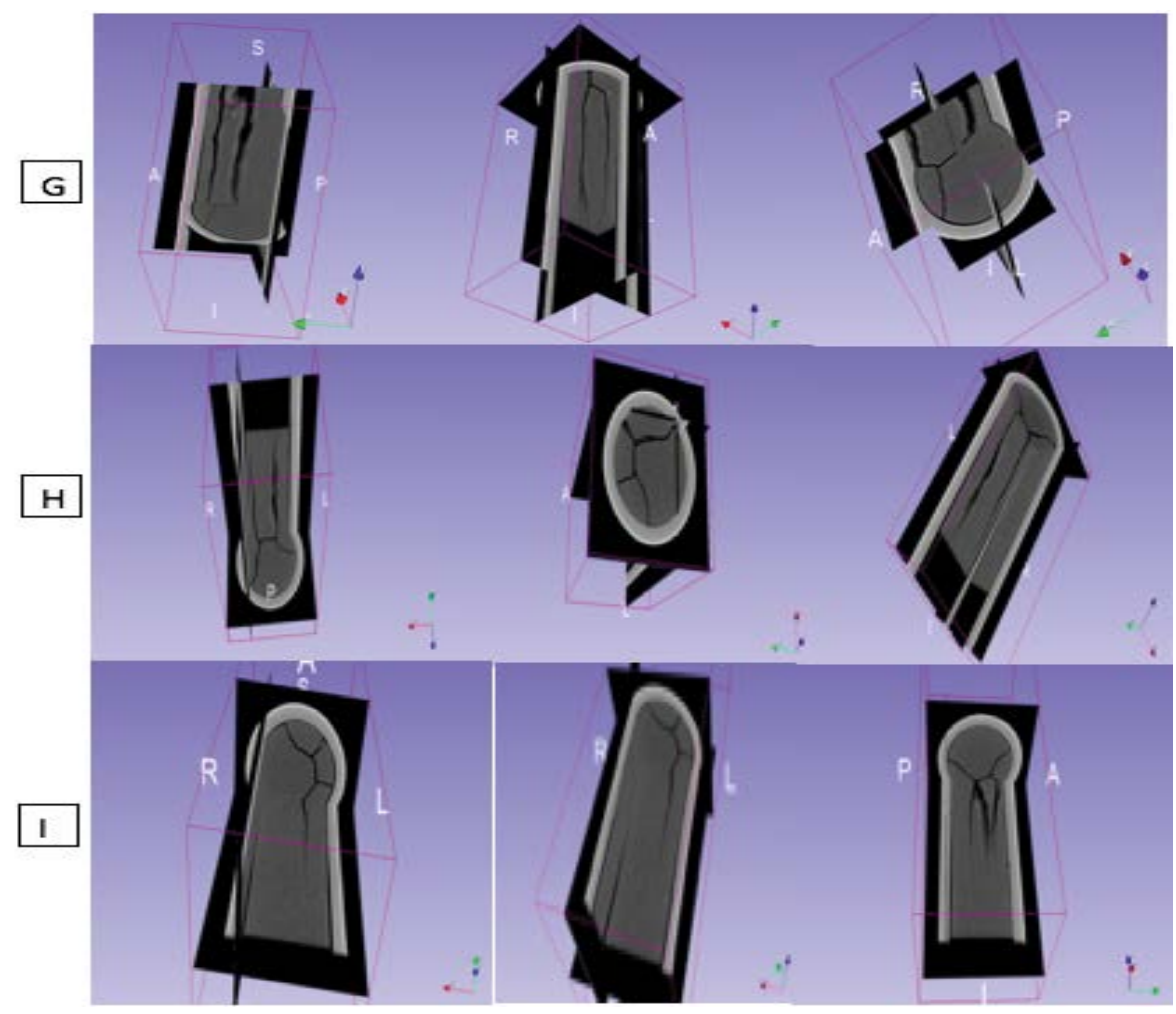

Figure 10: 3D images for sandstone samples $\mathrm{G}, \mathrm{H}$, and I corresponding to $\mathrm{S} 1, \mathrm{~S} 2$, and $\mathrm{S} 3$ respectively.

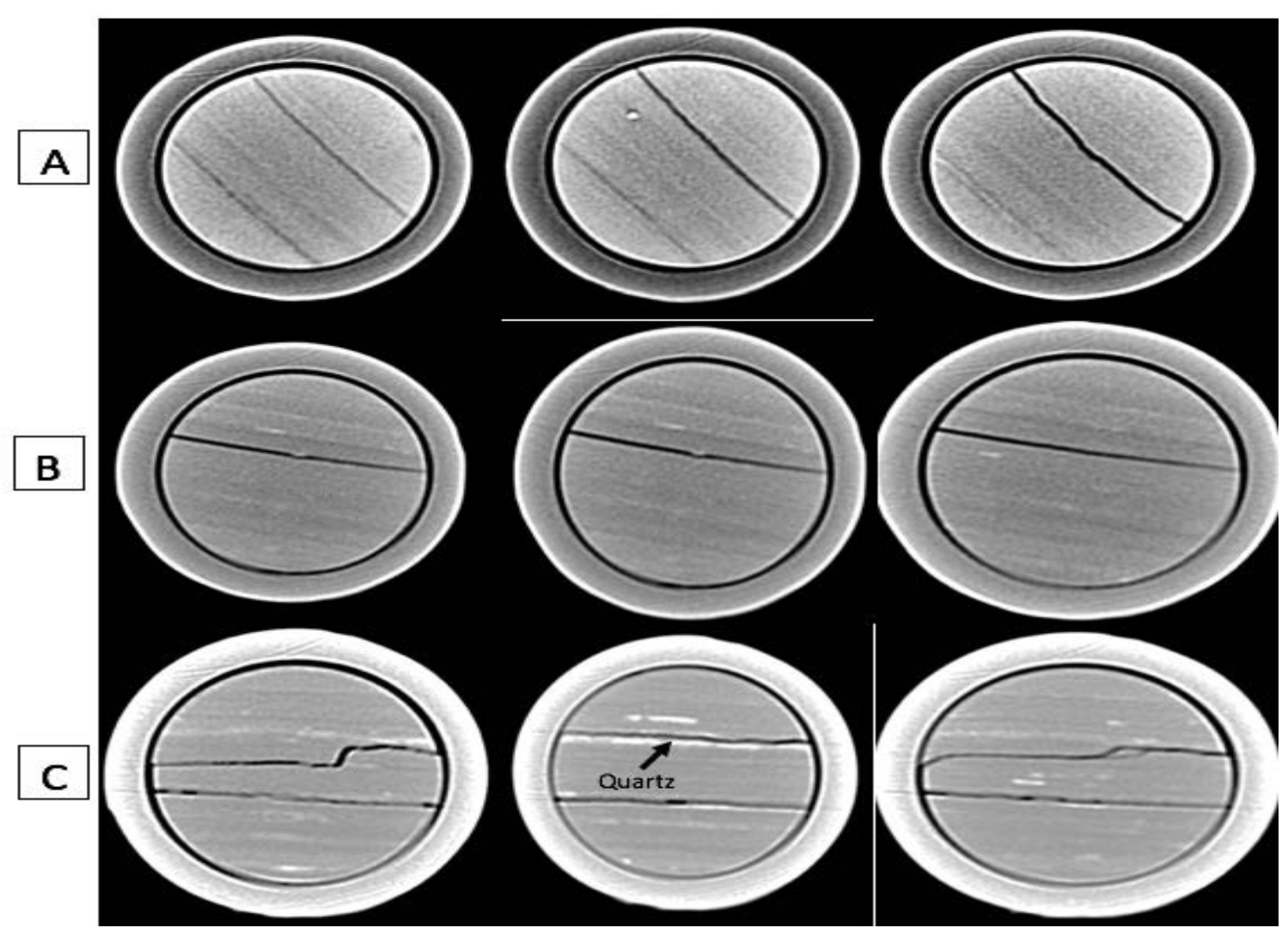

Figure 11: CT scan 2D images for shale samples: A, B, and C are corresponding to Sh1, Sh2, and Sh3 respectively. 
Citation: Susi AO, Mahrous MA, Elwegaa KA, Sims PL, Heinz IR, et al. (2018) Optimization of Composite Layering Effect Based on Measured Formation Fracture Height to Length Ratios. J Pet Environ Biotechnol 9: 376. doi: 10.4172/2157-7463.1000376

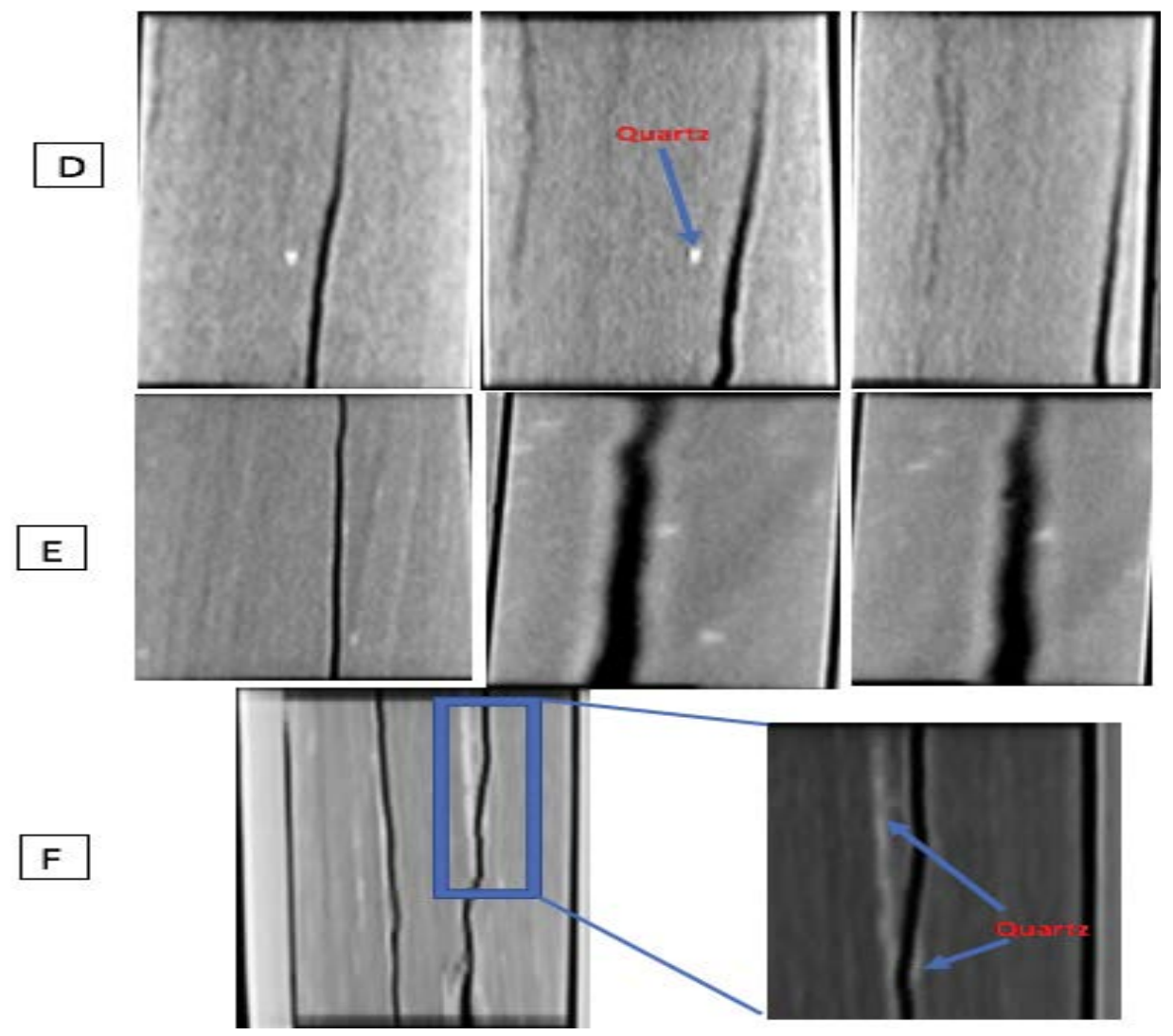

Figure 12: Multiplanar reconstruction (MPR) images XZ view for shale samples. D, E, and F correspond to Sh1, Sh2, and Sh3 respectively.

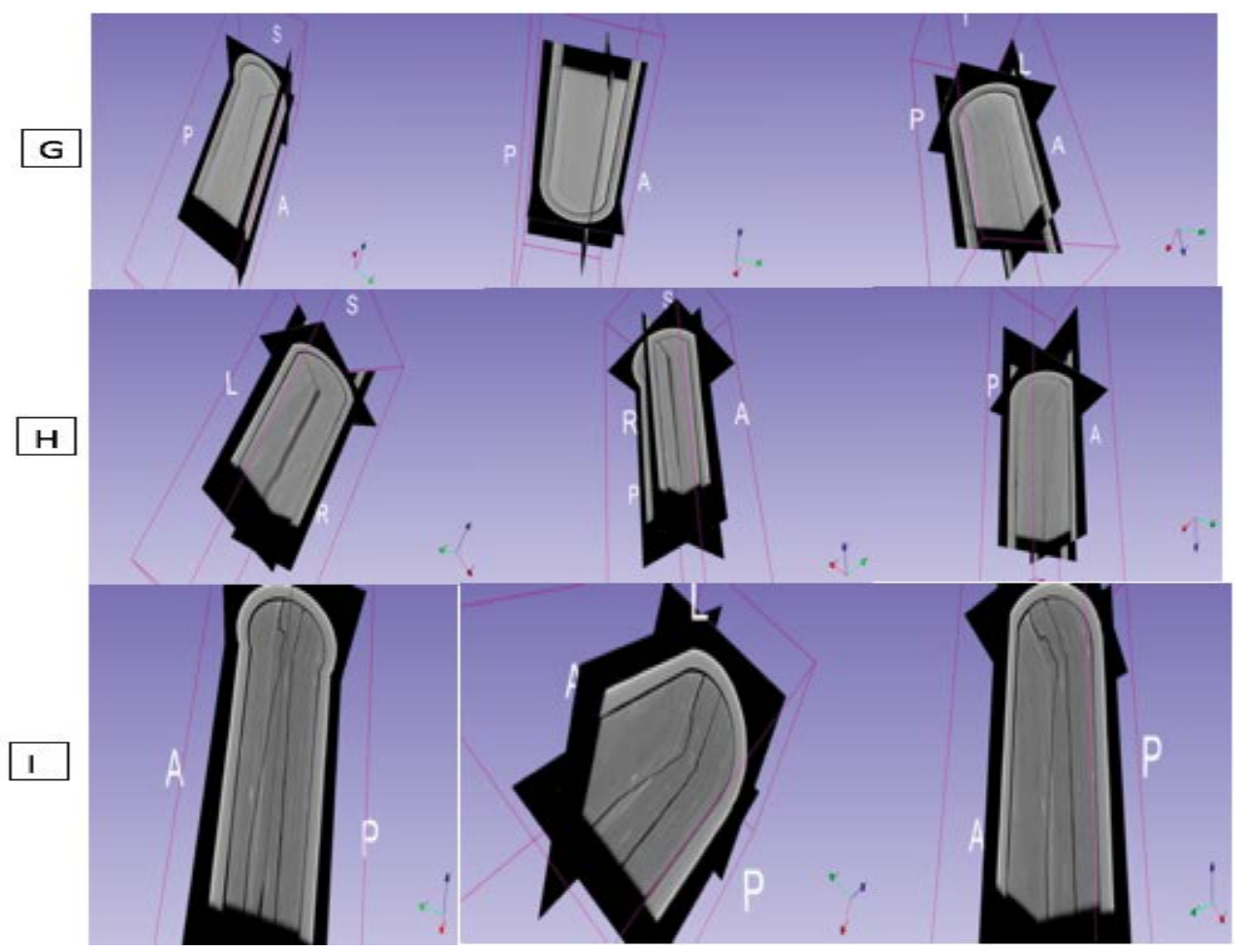

Figure 13: 3D images for shale samples $\mathrm{G}, \mathrm{H}$, and I corresponding to Sh1, Sh2, and Sh3 respectively. 
Citation: Susi AO, Mahrous MA, Elwegaa KA, Sims PL, Heinz IR, et al. (2018) Optimization of Composite Layering Effect Based on Measured Formation Fracture Height to Length Ratios. J Pet Environ Biotechnol 9: 376. doi: 10.4172/2157-7463.1000376

due to a higher fracture threshold [25]. The fracture apparatus of the preexisting fracture observed in shale sample $\mathrm{Sh}_{3}$ appeared to increase in width after the hydraulic fracturing procedure (Figure 13).

\section{Conclusions}

The effects of the mineralogical and chemical constituents on CLE value of sandstone and shale samples were investigated using XRD, $\mathrm{XRF}$, and CT scanning analysis. Based on the study presented herein, the following conclusion was derived.

1. The mineralogical and chemical behavior of the rock sample has a significant effect on the CLE values.

2. Quartz and clay content has the strongest influence on the CLE value due to the brittle behavior of quartz and ductile behavior of clay minerals (nacrite).

3. Despite the presence of small concentrations of clay minerals (nacrite) in shale samples, they significantly influence CLE values.

4. The CLE value for shale sample $\mathrm{Sh}_{3}$ was the highest among the shale samples which could be due to the presence of a preexisting fracture. This phenomenon could be explained by the fact that the preexisting crack will absorb the majority of the applied force before another crack will start to develop and the high Young's modulus value of the sample.

5. The method of X-ray computed tomography can be used as an excellent nondestructive technique to visualize hydraulically induced fractures in $3 \mathrm{D}$.

6. The fracture pattern developed in shale samples were mainly parallel to one another, perpendicular to the applied force, and did not form a fracture network. The fractures developed in sandstones however, start from the bottom of the sample in parallel orientation and then merge together to form connected fracture networks.

7. The fracture apparatus of sandstone samples was largest at the bottom of the sample and narrows as it propagates upwards. The fracture apparatus of shale was roughly constant throughout the sample.

\section{References}

1. Fisher MK, Warpinski NR (2011) Hydraulic fracture-height growth: Real data Society of Petroleum Engineers, Colorado, USA.

2. Teufel LW, Clark JA (1984) Hydraulic fracture propagation in layered rock: Experimental studies of fracture containment. Soc Petrol Eng J 24: 19- 32.

3. Soliman MY, Byrd A, Walters H, Weijers L (2004) Reservoir-based fracture optimization approach. SPE International Thermal Operations and Heavy Oil Symposium and Western Regional Meeting, California, USA.

4. Ding W, Chao L, Chunyan L, Xu C, Jiu K, et al. (2012) Fracture development in shale and its relationship to gas accumulation: Geosci Front 3: 97-105.

5. Ding WL, Zhang BW, Li TM (2003) Formation of non-tectonic fractures in mudstone in Gulong depression. Oil and Gas Geology 24: e50-e54.
6. Ketcham RA, Slottke DT, Sharp JM (2010) Three-dimensional measurement of fractures in heterogeneous materials using high-resolution X-ray computed tomography. Geosphere 6: 499-514.

7. Zabler S, Rack A, Manke I, Thermann K, Tiedemann J, et al. (2008) Highresolution tomography of cracks, voids and micro-structure in greywacke and limestone: Journal of Structural Geology 30: 876-887.

8. Geet MV, Swennen R (2001) Quantitative 3D-fracture analysis by means of microfocus X-Ray Computer Tomography $(\mu \mathrm{CT})$ : An example from coal. Geophys Res Lett 28: 3333-3336.

9. Skinner JT, Tovar FD, Schechter DS (2015) Computed tomography for petro physical characterization of highly heterogeneous reservoir rock. SPE Latin American and Caribbean Petroleum Engineering Conference, Quito, Ecuador.

10. Mahrous M (2017) Quantitative 3D analysis for natural micro- fracture in Woodford shale, southern Oklahoma, using Non-destructive micro-computer tomography technique. Texas Tech University, Lubbock, Texas, USA.

11. Susi O, Sims L, Sharma S, Elwegaa KA, Mahrous MA, et al. (2018) Effect of lithology barriers and composite layering on fracture height in unconventional reservoirs. Int J Eng Sci 7: 8-19.

12. Hounsfield GN (1973) Computerized transverse axial scanning (tomography) I: Description of system. Br J Radiol 46: 1016-1022.

13. Ketcham RA, Carlson WD (2001) Acquisition, optimization and interpretation of $\mathrm{X}$ ray computed tomographic imagery: applications to the geosciences. Comput Geosci 27: 381-400.

14. Baker DR, Mancini L, Polacci M, HigginsMD, Gualda GA, et al. (2012) An introduction to the application of X-ray microtomography to the threedimensional study of igneous rocks: Lithos 148: 262-276.

15. Van Geet M, Swennen R, Wevers M (2000) Quantitative analysis of reservoi rocks by microfocus X-ray computerized tomography. Sediment Geol. 132 25-36.

16. Taud H, Martinez-Angeles R, Parrot JF, Hernandez-Escobedo L (2005) Porosity estimation method by X-ray computed tomography: J Petrol Sci Eng 47: 209-217.

17. Raju PD, Neelima G (2012) Image segmentation by using histogram thresholding. Int J Comput Eng Inf Technol 2: 776-779.

18. Fisher M (2017) Round robin comparison of composition based mineralogical studies of unconventional reservoirs, Texas Tech University, Texas Tech University Library, USA.

19. Djebbar T, Donaldson DE (2004) Theory and Practice of Measuring Reservoir Rock and Fluid Transport Properties (4th edn), Petrophysics, Gulf Professional Pub, Texas, USA.

20. www.ner.com/site/systems/autolab-series/autolab-1500.html

21. Emadibaladehi S (2014) Investigation of effects of temperature and swelling on wellbore stability in unconventional reservoirs. Department of Petroleum Engineering, Texas Tech University, USA.

22. Zhang C, Gamage R, Perera M, Zhao J (2017) Characteristics of Clay Abundant Shale Formations: Use of $\mathrm{CO}_{2}$ for Production Enhancement: Energies 10: 1887

23. Jarvie DM, Hill RJ, Ruble TE, Pollastro RM (2007) Unconventional shale-gas systems: The Mississippian Barnett Shale of north-central Texas as one mode for thermo genic shale-gas assessment: Am Assoc Pet Geol Bull 91: 475-499.

24. Buller D, Hughes SN, Market J, Petre JE, Spain DR, et al. (2010) Petro physica evaluation for enhancing hydraulic stimulation in horizontal shale gas wells. SPE Annual Technical Conference and Exhibition, Florence, Italy.

25. Martineau DF (2001) Newark East, Barnett Shale field, Wise and Denton counties, Texas; Barnett Shale frac-gradient variances (abs): AAPG Southwest Section Meeting, Fort Worth Geological Society, Texas, USA. 